\title{
Evolution of Liver Transplantation Program in Shiraz, Iran
}

\author{
Seyed Ali Malek Hosseini, ${ }^{1}$ Saman Nikeghbalian, ${ }^{1}$ Heshamtollah Salahi, ${ }^{1}$ Koroush Kazemi, ${ }^{1}$ Alireza \\ Shemsaeifar, ${ }^{1}$ Ali Bahador, ${ }^{1}$ Mohsen Dehghani, ${ }^{2}$ Mohamad Hadi Imanieh, ${ }^{2}$ Reza Tabrizi, ${ }^{3}$ and Kamran \\ B. Lankarani $\mathrm{i}^{4, *}$ \\ ${ }^{1}$ Shiraz Transplant Research Center, Shiraz University of Medical Sciences, Shiraz, IR Iran \\ ${ }^{2}$ Pediatric Gastroenterology and Hepatology Department, Shiraz University of Medical Sciences, Shiraz, IR Iran \\ ${ }^{3}$ Health Policy Research Center, Institute of Health, Student Research Committee, Shiraz University of Medical Sciences, Shiraz, IR Iran \\ ${ }^{4}$ Health Policy Research Center, Institute of Health, Shiraz University of Medical Sciences, Shiraz, Iran \\ "Corresponding author: Kamran B. Lankarani, MD; Health Policy Research Center, Institute of Health, 8th Floor, Building No. 2, School of Medicine, Zand Avenue, Shiraz, IR Iran. \\ Tel/Fax: +98-7132309615, E-mail: lankaran@sums.ac.ir
}

Received 2017 August 22; Revised 2017 September 30; Accepted 2017 October 08.

\begin{abstract}
Background: Liver transplantation (LT) is the only approved treatment for patients with end stage liver disease (ESLD). Shiraz organ transplantation center (SOTC) was the first center in Iran to provide LT. This report is on the evolution of LT program in this center. Methods: We report the clinical features and outcomes of all those who received LT between May 15, 1993 to December 31, 2015 as well as donor features. All LT were performed at Namazi hospital in Shiraz, Iran. The Kaplan-Meier and multivariate Cox proportional hazards regression analyses were performed to determine prognostic factors and the overall long-term survival after liver transplantations.

Results: During this period, 3191 recipient patients received LT from 3110 donors. Overall patient survival rates were $84 \%$ at 1 year, $80 \%$ at 5 years, and $73 \%$ at 10 years. The survival rates for recipients from living donors were $74.0 \%$ at 1 year and $70.0 \%$ at 5 years compared to $86.0 \%$ at 1 and $81.0 \%$ at 5 years for recipients from deceased donors $(\mathrm{P}<0.0001)$. The survival rates of LT for 2 different Era I (1993 - 2005) and II (2006 - 2015) were estimated to be $76.0 \%$ vs. $85.0 \%$ at one year, $69.0 \%$ vs. $81 \%$ at 5 years, and $60.0 \%$ vs. $78.0 \%$ at 10 years, respectively $(\mathrm{P}<0.0001)$.The most common indications for LT were cryptogenic cirrhosis, hepatitis B, primary sclerosing cholangitis, autoimmune hepatitis, and metabolic liver diseases during this period.

Conclusions: LT is now an affordable treatment for patients with ESLD in Iran with acceptable survival, which has further been improved in recent years.
\end{abstract}

Keywords: Liver Transplantation, Iran, Cirrhosis, End Stage Liver Disease, Organ Donation, Fattwa

\section{Background}

With a relative increase in the recognition of patients suffering from end stage liver disease (ESLD) and liver cancers, there is an increase in demand for their treatments. Liver transplantation (LT) is considered the only standard treatment for these patients (1). The annual rate of LT was estimated to be 3.63 per million inhabitants globally in 2014, which was performed in 107 centers in 5 continents, but most of these centers had less than 100 patients per year (2). Despite the raising numbers of LT centers worldwide, there is still $13.8 \%$ death rate in the patients with end stage liver disease in waiting lists based on United Network for Organ Sharing database (3). This figure does not include those who were not candidates for LT despite ESLD due to comorbid conditions or contraindications. Furthermore, LT is not affordable for many patients with ESLD due to financial problems and other barriers for utilization (4). Improved surgical techniques and better preoperative care including availability of better protocols of immunosuppressive treatments have improved outcomes of LT including survival of recipients (5-7). Despite this improvement, there is still an excess risk of death in long- term survivors with an estimated loss of 7 years of life compared to 6 and age matched general population, with a greater difference in younger recipients (8).

Understanding the risk factors of premature death in recipients would be very helpful in providing long- term care for these patients. There are multiple factors affecting the survival both from the donor and the recipient side including age, gender, ethnicity, MELD/PELD scores, comorbid conditions, surgical techniques, type of immunosuppressive drugs, and even socioeconomic status (9-12).

Launching LT like any other sold organ transplantation programs has an ethical and legal issue closely related to the legislative context. In many Islamic countries, there is still a debate among the religious communities on admissibility of solid organ transplantation from de- 
ceased donors. After a long discussion on this issue in both academic and religious communities in Iran, finally in May 1989 the late Imam Khomeini announced his historic Fatwa on eligibility of use of organs from deceased donors to save the lives of recipients. This historic Fatwa facilitated the path for promotion of solid organ transplantation in Iran. Based on this Jurisprudence support, on June 2000 Iranian parliament approved the organ transplantation brain death act. According to this law and its bylaws, while organ transplantation in Iran is prohibited for foreign recipients, donation from deceased donors became possible. Based on strict criteria, with approval by a medical committee not attached to the transplantation team and after obtaining the consent of the legal possessors of the victim, organs could be harvested, but they need to be transplanted only in public hospitals.

Based on this religious permission, the first liver transplantation was performed in Shiraz (the capital of Fars province in south of Iran) in 1993 after gaining approval by Fars province Judiciary. The number of recipients of LT have increased gradually to 4 in 2000 (7) and then to 534 in 2015 , with the total number of recipients reaching over 3000 cases at the end of 2015.

\section{Objectives}

This report is aimed at reviewing the current status of the LT in Shiraz, Iran, which started 24 years ago. This study of evolution of LT program in Shiraz in a religious community with strict laws on organ donation may help other centers worldwide to improve their performance.

\section{Methods}

This was a retrospective study of liver transplantation in Shiraz. All patients who received LT form the start of the program until December 31, 2015 were included. All transplants were performed at Namazi hospital, which is a major referral center for liver transplantation in Iran. Demographic data as well as clinical and laboratory characteristics were obtained by retrospective review of medical records. The survey questionnaires included data of the donors and recipients' information including age, sex, body mass index (BMI), blood group, etiology of ESLD, MELD/PELD of the recipients, date of transplantation, type of donors, duration of transplantation surgery, surgical technique, length of hospital stay, and length of stay in intensive care unit after the transplantation. In addition, retransplantation rate, cause of retransplantation, status at last follow- up, and cause of death were reviewed. Followup was considered as complete with either the patient's death or surgery dates after December 31, 2015.The study protocol was approved by the ethics committee of Shiraz University of Medical Sciences.

As the support program for LT launched by Iranian Ministry of Health and Medical Education (MOHME) in 2005 covered all the in hospital costs of LT, we compared the data of LT recipients before and after this program.

All statistical analyses were done using the SPSS software package for Windows, Version 22 (SPSS Inc., Chicago, USA) and Stata Version 11 (STATA Corporation, College Station, TX). Continuous variables are presented as mean \pm standard deviation or Median [IQR]. The Qualitative variables are presented as number and number (percent). The Kaplan-Meier method was used to calculate observed survival, and log-rank statistics was used to compare the differences in survival curves. Also, multivariate Cox proportional hazards regression analysis was performed to determine prognostic factors in overall long-term survival after adjusting for demographic and clinical factors. Two-tailed tests were performed and a P value less than 0.05 was considered statistically significant.

\section{Results}

During this period, 3191 patients (1226 women) received LT from 3,110 donors, with mean \pm SD age of recipients being $32.4 \pm$ 18.3.The demographic and clinical characteristics of patients are presented in Table 1.

Of all LT, 25.2\% were performed for pediatric recipients. The annual number of LT based on age groups (age 18 years and younger (pediatrics) and older than 18 years old (adults) are demonstrated in Figure 1.

During this period, the mean of MELD and PELD scores of patients decreased in Shiraz, which was statistically significant $(\mathrm{P}<0.0001)$ (Figure 2$)$.

The study subjects were divided into 2 eras (Era I from 1993 to 2005 and Era II from 2006 to 2015) based on date of LT. As presented in Table 2, there were significant differences between some demographic and clinical characteristics in these eras.

There were 58 retransplantations in the study period, of which $73 \%$ were performed within the first 15 days after transplantation. Of different etiologies of ESLD, HBV and $\mathrm{AIH}$ had higher rates of retransplantation, which were done in $2.36 \%$ of patients transplanted with HBV and $2.01 \%$ with AIH (Table 3).

Overall patient survival rates were $84 \%$ at 1 year, $80 \%$ at 5 years, and $73 \%$ at 10 years. The survival rates of LT for Era I and II were $76.0 \%$ vs. $85.0 \%$ at 1 year, $69.0 \%$ vs. $81 \%$ at 5 years, and $60.0 \%$ vs. $78.0 \%$ at 10 years, respectively $(\mathrm{P}<0.0001)$.

The mean \pm SE of survival time of the recipients when categorized by donors' age groups were $11.56 \pm 0.44$ for 


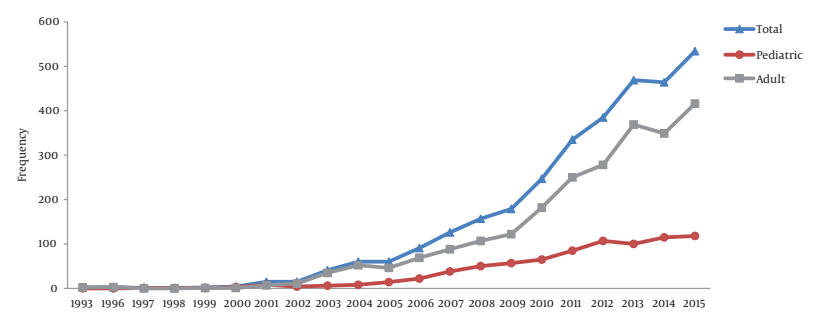

Figure 1. Annual Number of LT in Shiraz, Iran by Age Group

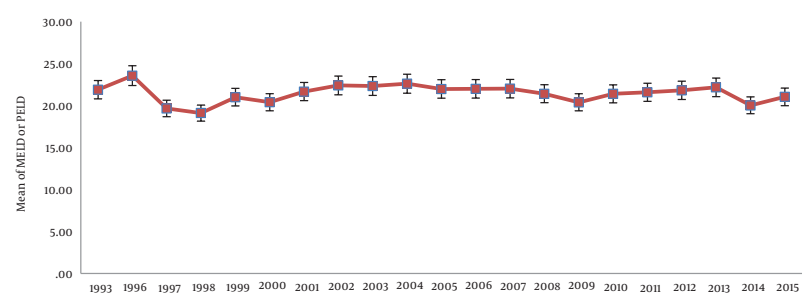

Figure 2. The Mean of MELD or PLED Among LTin Different Years in Shiraz, Iran

donors aged younger than 15 years, $11.80 \pm 0.15$ for donors aged 15 to 50 years, and $11.79 \pm 0.16$ for those donors aged more than 50 years $(\mathrm{P}=0.081)$.

LT had a better survival when female patients received liver from female donors compared to other groups (mean \pm SE survivals were with $12.11 \pm 0.29$ in female donors to female recipients, $11.89 \pm 0.23$ in male donors to male recipients, $11.41 \pm 0.21$ in male donor to female recipients, and $10.30 \pm 0.35$ in female donors to male recipients, respectively $(\mathrm{P}=0.037)$ )(Figure 3). The highest 5-year survival rate of LT was in autoimmune hepatitis and PSC and the least 5year survival rate was for $\mathrm{HCC}(\mathrm{P}<0.0001)$ (Figure 3$)$.

In univaraite analysis, recipient age (comparing adult and pediatric recipients) $(\mathrm{P}<0.0001)$, graft type $(\mathrm{P}<$ 0.0001), donor age $(P=0.019)$, donor sex $(P=0.008)$, donor situations $(\mathrm{P}<0.0001)$, duration of transplantation surgery $(\mathrm{P}<0.0001)$, and the MELD/PELD score of the recipients $(\mathrm{P}<0.0001)$ had a correlation with recipients' survival.

In analysis for multivariate Cox proportional hazard regression model, all variables with P value less than 0.2 in univaraite analysis were entered into the Cox model. The results of this model are presented in Table 4.

\section{Discussion}

According to the article four of the constitution of the Islamic Republic of Iran all laws and regulations in Iran must be based on Islamic criteria. There has been a debate among the scholars on allowance of transplantation from deceased donors. The historical Fatwa of late Imam Khomeini on May 21, 1989, which was further emphasized by his successor Ayatollah Khamenei, gave an important momentum to the transplantation community in Iran. This opportunity led the Shiraz team to think on feasibility of liver transplantation in Iran. At the time, the only opportunity for those with ESLD in Iran was receiving LT from their relatives. We are now following dozens of these patients who received LT, mainly from living donors, mostly in UK and USA. This type of transplantation tourism was too expensive and not affordable for most Iranian patients with ESLD as most patients with ESLD were from low socioeconomic families. After discussions with the ministry of health and medical education (MOHME) of Iran, Shiraz University of Medical Sciences (SUMS) was chosen to be the main center for LT in Iran few months later. The reasons for this selection were good reputation of SUMS for team work and its experience in kidney transplantation as the first case of kidney transplantation was done in Namazi hospital in Shiraz, the capital of Fars province in 1967.

A group of surgeons, anesthesiologists, and hepatologists from SUMS were selected to go overseas for professional development in this field. This group was directed by the first author of this manuscript, and in the first stage, they were kindly accepted as research fellows in transplantation by late professor Thomas E. Starzlin Pittsburgh, USA. The team also visited other centers in Japan and UK, especially for adopting the techniques of living transplantation and organizing the liver intensive treatment unit (LITU). With these capacities, the first liver transplantation was 

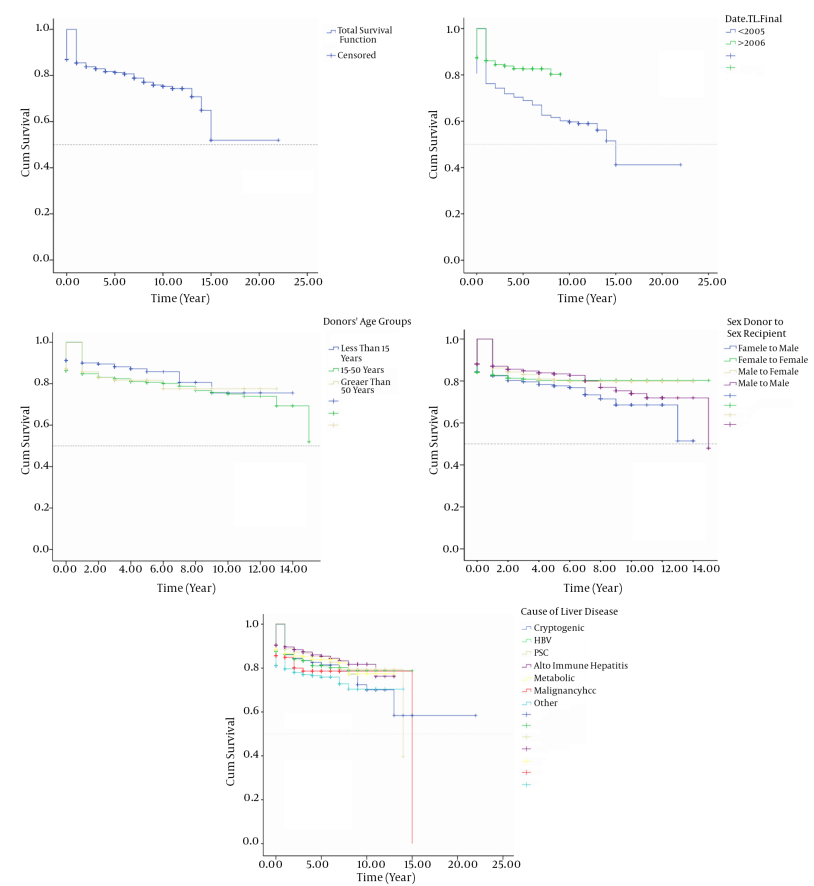

done in 1993 in Shiraz after obtaining legal approval of the brain dead status of the deceased donor through the Judiciary system because at that time there was no approved law for the brain dead by the parliament. The first case was a patient with hepatitis B and Child- Pugh Score of 13 who died 24 hours after receiving LT due to circulatory and renal failure. However, the good point was that there was no problem with the surgical technique. Within a week, the second case, a 28- year- old male with HBV induced cirrhosis was transplanted from a deceased donor. This patient is still alive after 24 years with good liver function and no recurrence of HBV. However, he was transplanted for end stage renal disease 2 years ago after 6 months of renal replacement therapy.

Since then, the program for LT in Shiraz has grown steadily and now the number of transplanted patients has reached to more than 500 cases annually. All of these activities are done in our transplantation ward with 28 beds and 10 LITU beds.

As shown in Figure 1, a dramatic surge of the number of transplanted patients is seen after 2005. There are several reasons for this rise. One of the important issues is the rise in number of organ donations. Although our center was the first center to perform living related liver trans- plantation in Iran and now more than $11 \%$ of our cases are receiving LT from their relatives, most of patients need to receive LT form deceased donors mostly because of lack of appropriate donors and the size of the recipient. In recent years through public enlightenment and community alerting programs, the numbers of people who fill the organ donation cards have increased dramatically in Iran. Engagement of different non-governmental organizations and bodies including clerics, social workers, and psychiatrics had a great impact on changing the culture for organ donation, and it is now becoming a norm rather than an exception when families are informed on the brain death status of their beloved patients. This has increased the willing to donate organs from deceased patients in Fars province from 3.1 per million population (PMP) in 2001 to 21.8 PMP in 2015. In general, this figure for Iran has also increased from less than 1 PMP in 2001 to 10.3 PMP according to data of International Registry in Organ Donation and Transplantation (13). This has placed the Islamic Republic of Iran in the first rank among all Islamic countries in organ donation with the next country having $40 \%$ lower donation rate. We think based on these experiences we can reach even higher deceased donation rate with more community engagement and with the support of other sectors specially 
Table 1. Patient Demographics and Disease Characteristics (Recipient $n=3191$; Dono $\mathrm{n}=3110)^{\mathrm{a}}$

\begin{tabular}{|c|c|}
\hline & Values \\
\hline Age of the recipients, $y[\min -m a x]$ & $32.4 \pm 18.3(0.04-74.0)$ \\
\hline Sex of the recipients: Male/Female [Ratio] & 1965/1226 [1.60] \\
\hline BMI of the recipients, $\mathrm{kg} / \mathrm{m}^{2}$ [min-max] & $22.8[10.24-48.3]$ \\
\hline Recipients blood group $(\mathbf{A} / \mathbf{B} / \mathbf{A B} / \mathbf{O})$ & 960/784/249/1188 \\
\hline MELD/PELD of the recipients (Median score), IQR & $21.0[18.0-23.4]$ \\
\hline Age of the donor, $y[\min -m a x]$ & $31.4 \pm 14.8[1.0-80.0]$ \\
\hline Sex of the donor: Male/Female [Ratio] & $2183 / 1008[2.16]$ \\
\hline BMI of the donor $(\mathrm{kg} / \mathrm{m} 2)[\mathrm{IQR}]$ & $24.5[22.2-26.6]$ \\
\hline Donor blood group (A/B/AB/O) & 914/747/200/1320 \\
\hline $\operatorname{LOS}(\mathrm{Day})[\mathrm{IQR}]$ & $12[10-16]$ \\
\hline ICU-LOS (Day) [IQR] & $7[4-10]$ \\
\hline Duration of Surgery (Minute) [IQR] & $300[240-375]$ \\
\hline \multicolumn{2}{|l|}{ Etiology } \\
\hline Cryptogenic cirrhosis & $524(16.4)$ \\
\hline HBV & $509(16.0)$ \\
\hline PSC & $412(12.9)$ \\
\hline Autoimmune hepatitis & $447(14.0)$ \\
\hline Metabolic liver diseases: & $388(12.2)$ \\
\hline Wilson & $227(7.1)$ \\
\hline Tyrosinemia & $80(2.5)$ \\
\hline Hyper Cholesterolemia & $39(1.2)$ \\
\hline Other & $21(0.7)$ \\
\hline Hyper Oxalemia & $12(0.4)$ \\
\hline Hemochromatosis & $9(0.3)$ \\
\hline HCC & $167(5.2)$ \\
\hline Other & $744(23.3)$ \\
\hline \multicolumn{2}{|l|}{ Type of grafts } \\
\hline Whole & $2682(84.0)$ \\
\hline Partial from living donor & $347(10.9)$ \\
\hline Split & $162(5.1)$ \\
\hline \multicolumn{2}{|l|}{ Donor situations } \\
\hline Deceased donor & $2844(89.1)$ \\
\hline Living donor & $347(11.4)$ \\
\hline Deaths up to end of 2015 & $552(17.3)$ \\
\hline Cause of death & \\
\hline Infection & $71(12.9)$ \\
\hline Chronic Rejection & $24(4.3)$ \\
\hline Renal Failure & $53(9.6)$ \\
\hline Cardiac event & $45(8.2)$ \\
\hline Surgical complications & $41(7.4)$ \\
\hline PNF & $39(7.1)$ \\
\hline Pulmonary event & $25(4.5)$ \\
\hline Other & $254(46.0)$ \\
\hline
\end{tabular}

ecclesiastics. Our assumption is that we have not reached the maximum deceased donation capacity in our community ye; and the reason may be that we have not started the program for non- heart- beating donors in our center because of its higher rates of complications and ultimately poor outcome and higher costs.

Another important issue on utilization of LT was the financial barriers. $\mathrm{LT}$ is one the most expensive treatments and its cost has been reported to be an important barrier for utilization of this live saving procedure, especially for most needy patients. Since November 2005 through an initiative by MOHME of Islamic Republic of Iran, all hospital costs for LT are totally covered by the government. This has increased utilization of this life saving procedure, especially in children, patients from lower socioeconomic classes, and those residing in more distant parts of the country (14). According to the parliamentary law, organ transplantation in Iran could only be done in public hospitals, and private hospitals are banned from performing any organ transplantation. As nearly $95 \%$ of the Iranian population including all rural residents, industry workers, and government employees are now covered by one of the public insurance programs, this has also contributed to provide better access to LT. Many drugs used in the care of LT patients including cyclosporine, azathioprine, and antivirals such as lamivudine and most recently new direct acting antivirals for hepatitis $\mathrm{C}$ are produced by local Iranian companies, which has reduced the cost of the medications as low as $5 \%$ of the imported drugs. For those drugs which are still imported such as thymoglobin, tacrolimus, and mycophenolate mofetil, the government has a subsidizing program, which reduces the cost to less than 5\%, and while patients are in the hospital the drugs are free (15-17). To compare, LT costs were not covered by national health insurance in Japan till 2004 (18). In the USA, the costs are fully covered by those who have insurance. It is interesting that in some states in the USA; for instance, in Texas, the Medicaid, which is the source of insurance for up to $18 \%$ of the population in this state, the cost is not accepted by most LT centers (18). Having private insurance in Ireland was associated with better access to LT (19). In most developed countries, the cost is covered by their universal health care programs either through insurance or national health system (20).

Shiraz was among the first centers to launch structured LT program in the Middle East. Saudi Arabia started the program in 1994 (21) and Lebanon in 1998 (22). Egypt, one of the pioneers in the field, has started LT from living donors in 1991, but there is still problems with implementing deceased donor programs despite passage of the law in Egyptian parliament in 2010 (23).

The main indications for LT in our center were as follow: cryptogenic cirrhosis, HBV infection, primary sclerosing cholangitis, autoimmune hepatitis, metabolic liver disease, and hepatocellular carcinoma (HCC). Consistent 
Table 2. Comparison of Demographic and Clinical Characteristics of Liver Transplantation Patients in 2 Different Eras of Transplantation ${ }^{\mathrm{a}, \mathrm{b}}$

\begin{tabular}{|c|c|c|c|c|}
\hline Characteristics & & Era I (1993 - 2005) & Era II (2006 - 2015) & PValue \\
\hline Number of recipients & & 206 & 2985 & - \\
\hline \multirow{7}{*}{ Etiology } & Cryptogenic cirrhosis & $50(24.5)$ & $474(15.9)$ & \multirow{7}{*}{$<0.0001$} \\
\hline & HBV & $36(17.5)$ & $473(15.8)$ & \\
\hline & PSC & $31(15.0)$ & $381(12.8)$ & \\
\hline & Autoimmune hepatitis & $40(19.4)$ & $407(13.6)$ & \\
\hline & Metabolic & $21(10.2)$ & $367(12.3)$ & \\
\hline & $\mathrm{HCC}$ & $2(1.0)$ & $165(5.5)$ & \\
\hline & Other & $26(12.6)$ & $718(24.1)$ & \\
\hline \multirow{2}{*}{ Median age of recipients } & Adult & $36.5[19-62]$ & $41[19-74]$ & $<0.0001$ \\
\hline & Pediatric & $13.0[0.11-18]$ & $7[0.04-18]$ & 0.001 \\
\hline \multirow{2}{*}{ Median age of Donors } & Adult & $29[19-78]$ & $34[19-80]$ & $<0.0001$ \\
\hline & Pediatric & $17.5[1-40]$ & $24[1-57]$ & $<0.0001$ \\
\hline \multicolumn{5}{|l|}{ Cause of death } \\
\hline \multirow{7}{*}{ Less than 30 days } & Infection & $8(25.0)$ & $33(12.0)$ & \multirow{7}{*}{0.052} \\
\hline & Surgical complications & $4(12.5)$ & $27(9.8)$ & \\
\hline & $\mathrm{PNF}$ & $1(3.1)$ & $38(13.8)$ & \\
\hline & Pulmonary Event & $4(12.5)$ & $10(3.6)$ & \\
\hline & Cardiac Event & $3(9.4)$ & $31(11.2)$ & \\
\hline & Renal Failure & $4(12.5)$ & $37(13.4)$ & \\
\hline & Other & $8(25.0)$ & $100(36.3)$ & \\
\hline \multirow{7}{*}{ Between 30 to180 days } & Chronic Rejection & $0(0.0)$ & $2(3.4)$ & \multirow{7}{*}{0.693} \\
\hline & Infection & $1(25.0)$ & $12(20.7)$ & \\
\hline & Surgery Complications & $0(0.0)$ & $2(3.4)$ & \\
\hline & Pulmonary Event & $0(0.0)$ & $4(6.9)$ & \\
\hline & Cardiac Event & $1(25.0)$ & $3(5.2)$ & \\
\hline & Renal Failure & $0(0.0)$ & $5(8.6)$ & \\
\hline & Other & $2(50.0)$ & $30(51.7)$ & \\
\hline \multirow{8}{*}{ More than 180 days } & Chronic Rejection & $16(31.4)$ & $6(4.6)$ & \multirow{8}{*}{$<0.0001$} \\
\hline & Infection & $3(5.9)$ & $14(10.7)$ & \\
\hline & Surgery Complications & $1(2.0)$ & $7(5.3)$ & \\
\hline & & & & \\
\hline & Pulmonary Event & $0(0.0)$ & $7(5.3)$ & \\
\hline & Cardiac Event & $1(2.0)$ & $6(4.6)$ & \\
\hline & Renal Failure & $2(3.9)$ & $5(3.8)$ & \\
\hline & Other & $28(54.9)$ & $86(65.6)$ & \\
\hline \multirow{3}{*}{ Number of death in different time } & Less than 30 days & $32(36.7)$ & $276(59.3)$ & \multirow{3}{*}{ - } \\
\hline & Between 30 to180 days & $4(4.6)$ & $58(12.5)$ & \\
\hline & Greater than 180 days & $51(58.7)$ & $131(28.2)$ & \\
\hline Duration of transplantation surgery (Minute) & & $433.1 \pm 99.6$ & $313.1 \pm 89.3$ & $<0.0001$ \\
\hline $\operatorname{LOS}$ (Day) & & $23[18-30]$ & $12[10-15]$ & $<0.0001$ \\
\hline
\end{tabular}

Abbreviations: LOS, length of stay; Res, retransplantations.

Values are expressed as number; No. (\%); median [min-max]; median [IQR]; mean \pm SD.

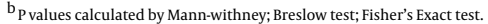

with the study performed by Adam et al. the main cause of end stage liver disease has changed over time (24). The number of recipients with HCC has increased from $1 \%$ to $5.5 \%$ of the recipients in the recent years in our center (Table 2). Many of cryptogenic cirrhosis cases in our center might be in fact patients with fatty liver disease, which is in raise in our nation (25). The numbers of patients with HBV, who receive LT are still high. This figure might be changed soon as we are observing the effect of national mass HBV vaccination for neonates in Iran, which started in 1993 and was expanded in $2007(26,27)$.

There was continuous improvement in our perfor- 
Table 3. Comparison of Demographic and Clinical Characteristics of Liver Retransplantation Patients in 2 Different Eras of Transplantation ${ }^{\mathrm{a}}$

\begin{tabular}{|c|c|c|c|c|}
\hline Characteristics & & Era I $(1993$ - 2005) & Era II (2006 - 2015) & Total Number Re Pernumber of Affected, \% \\
\hline \multicolumn{5}{|l|}{ Etiology of ESLD } \\
\hline & Cryptogenic cirrhosis & $0(0.0)$ & $4(7.1)$ & 0.76 \\
\hline & HBV & $1(50.0)$ & $11(19.6)$ & 2.36 \\
\hline & PSC & $0(0.0)$ & $7(12.5)$ & 1.70 \\
\hline & Autoimmune hepatitis & $0(0.0)$ & $9(16.1)$ & 2.01 \\
\hline & Metabolic & $0(0.0)$ & $5(8.9)$ & 1.29 \\
\hline & Malignancy HCC & $0(0.0)$ & $3(5.4)$ & 1.80 \\
\hline & Other & $1(50.0)$ & $17(30.4)$ & 2.42 \\
\hline \multicolumn{5}{|c|}{ Median age of recipients } \\
\hline & Adult & $44[1$ case] & $39[30-48]$ & - \\
\hline & Pediatric & $3[1$ case $]$ & $11[2-18]$ & - \\
\hline \multicolumn{5}{|c|}{ Median age of Donors } \\
\hline & Adult & $19[1$ case $]$ & $35[19-62]$ & - \\
\hline & Pediatric & $10[1$ case $]$ & $5.5[2-18]$ & - \\
\hline \multicolumn{5}{|l|}{ Time of Re } \\
\hline & Less than 15 days & $2(100.0)$ & $41(73.2)$ & - \\
\hline & Between 16 to 30 days & $\cdot$ & $5(8.9)$ & \\
\hline & More than 31 days & . & $10(17.9)$ & \\
\hline
\end{tabular}

Table 4. Risk Factors for Mortality in Liver Transplant Recipients by Using Multivariate Analysis ${ }^{\mathrm{a}}$

\begin{tabular}{|c|c|c|c|c|c|c|}
\hline Significant Predictors ${ }^{\mathbf{b}}$ & в & SE & HR & \multicolumn{2}{|c|}{ 95.0\% CI for HR } & PValue \\
\hline Cryptogenic cirrhosis & - & 0 & 1 & \multicolumn{2}{|c|}{ Reference } & - \\
\hline HBV infection & 0.030 & 0.175 & 1.031 & 0.732 & 1.452 & 0.862 \\
\hline PSC & -0.319 & 0.206 & 0.727 & 0.485 & 1.089 & 0.112 \\
\hline Autoimmune hepatitis & -0.332 & 0.197 & 0.718 & 0.487 & 1.057 & 0.093 \\
\hline Metabolic liver diseases & -0.176 & 0.204 & 0.838 & 0.562 & 1.250 & 0.387 \\
\hline HCC & 0.424 & 0.239 & 1.528 & 0.956 & 2.443 & 0.076 \\
\hline Other & 0.291 & 0.158 & 1.337 & 0.982 & 1.822 & 0.065 \\
\hline \multicolumn{7}{|l|}{ Type of donor grafts } \\
\hline Whole & - & 0 & 1 & \multicolumn{2}{|c|}{ Reference } & \\
\hline Partial from living donor & 0.697 & 0.153 & 2.008 & 1.487 & 2.712 & $<0.0001$ \\
\hline Split & 0.875 & 0.173 & 2.399 & 1.710 & 3.366 & $<0.0001$ \\
\hline Duration of transplantation surgery (Minute) & 0.003 & 0.000 & 1.003 & 1.002 & 1.004 & $<0.0001$ \\
\hline MELD/PELD of the recipients & 0.047 & 0.009 & 1.048 & 1.031 & 1.066 & $<0.0001$ \\
\hline
\end{tabular}

Abbreviations: Cl, Confidence interval; HR, Hazard ratio.

${ }^{a}$ Data are analyzed by multivarible Cox Regression.

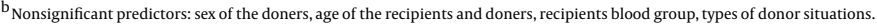

mance during these 2 decades. For instance, the duration of surgery and hospital stay have decreased while both short- term and long- term survivals have increased. Overall, our patients' survival rates at 1, 5, 10, and 15 years were $84.0 \%, 80 \%, 73.0 \%$, and $43 \%$, respectively, which is quite comparable with international results. This has become even better in recent years despite the transplantation of patients with extreme ages. For instance, the median age of our pediatric age group has decreased from 13 to 7 years and in adults from 36 to 41 years. In univaraite analysis of our series, the recipients' age and MELD/PELD score at the time of transplantation were significantly associated with overall survival after LT. In multivariate analysis only MELD/PELD score, but not the age, was related to recipients' survival. There are controversial reports on the association of baseline MELD/PELD score with survival (28-31).

Most of our patients were transplanted before the age of 60 and our retrospective study in relatively young Ira- 
nian population may have limitation to show the effect of the elderly on survival after LT. There is a need for large prospective studies to find the exact relationship, which might not be similar between different populations.

The etiology of underlying liver disease was also a strong predictor of long- term survival after LT in univariate analysis. The best survival rates were obtained in our series with primary sclerosing cholangitis followed by metabolic liver diseases, and autoimmune hepatitis. This might be related to the young age of these patients. In contrast, the worst survivals were with HCC followed by HBV. This is in concordance with other studies, which found higher mortality in LT recipients with HCC and HBV (24, $32,33)$.These findings were not confirmed in multivariate analysis of our data.

Similar to findings of Wong et al. our data revealed that longer operation room time was an independent predictor of death after LT in multivariate analysis (34). There was no significant association between the recipients' survival rates and length of hospital stay in total or their stay in LITU after controlling by confounding variables.

Among donor variables in univariate analysis, the donors' age, sex, type of donor, and graft type at the time of transplantation were significantly associated with overall survival after LT. In multivariate analysis, living donors as well as use of split organ were associated with higher mortality. This may be related to more difficult operation with higher rate of postoperative complications including vascular and biliary complications. Considering organ shortage, the use of split organ and living donors might be on rise globally and this increasing trend could be seen in our center.

There are reports that older age of donors is associated with higher mortality of the recipients (35). More than $60 \%$ of our donors aged between 19 to 45 years. In this relatively young donor age, it might be difficult to see the independent effect of age of donors on survival (36). However, we observed that the share of PNF as a cause of death has increased in our series in recent years (Table 2). This might be related to use of more border line donors by our team due to organ shortage.

The effect of sex match between donor and recipient has been shown in previous reports $(37,38)$. In this series in univariate analysis, survival rates of patients receiving organ from matched groups (female-female, male-male) was much better in the long-term, when compared to mismatched group (male-female or female-male) (39). However, there are other reports such as that of Schoening et al. which proposed that the effect of sex mismatch might be related to donor quality and recipient characteristics and not the gender mismatch (40).

Better access to newer immune suppressants and more adherences of our patients to their complex drug use have decreased the share of chronic rejection as the cause of death in our patients during time. This was despite the lower education and lower socioeconomic class of our patients in recent years. This indicates the importance of financial support which almost eliminated the financial barrier to utilization of drugs as well as the better performance of our team in patients' education and follow- up. Unfortunately, we have recently experienced some problems with continuous flow of imported drugs due to the newly imposed sanction on bank operation of the drug companies with Iran by the new government of the USA, which we hope could be solved soon.

We had the opportunity to perform retransplantation in 58 of our patients, most of which were done in the first 2 weeks after LT due to PNF or hepatic artery thrombosis not responding to radiologic interventions. Among all etiologies, the need for retransplantation was highest in patients with AIH and HBV induced liver disease (Table 3).

The age of adult recipients have increased in our center as mentioned before and now we have a growing number of patients receiving LT in their sixties in the past 5 years. Moreover, the causes of death have shifted from direct complications of the LT to cardiac events and the adverse effects of immune suppression (Table 2).

Our center was committed both to excellence in service and academic responsiveness. In this regard, this center was the educational hub for LT training not only for the nation but also for the regions. We have trained transplant surgeon, transplant hepatologits, LITU nurses, transplantation coordinators for 8 centers in Iran and other countries including Pakistan, Afghanistan, Tajikistan, Sudan, Syria, and Lebanon. Currentl, structured programs for LT is going on in 2 centers in Tehran, 1 center in Mashhad, 1 in Tabriz, 1 in Ahvaz, and 1 in Kerman. Except for Tehran, all other program implementers had their team trained in Shiraz. We have also published more than 100 articles on clinical and basic aspects of LT including stem cell transplantation.

Our story on evolution of LT in Shiraz is a long journey from hopes to realities, which became through by good will, hard team work, governmental support, and community engagement despite post war situation of Iran at the beginning and the current sanctions. We hope reviewing our experience help other centers in developing countries to expand their transplantation programs not as a program for prestige but as a need for the most disadvantaged patients. 


\section{Acknowledgments}

This work was not possible without the help our hard working staff in coordination team, operating theater, LITU and transplantation ward of Namazi hospital. We want to specially thank Mr. Siavash Gholami and Miss Parisa Janghorban for their helps in gathering these data. This study was partly supported by health policy research center, institute of health, at Shiraz University of medical sciences.

\section{Footnote}

Conflict of Interest: KBL was the minister of health and medical education of Islamic republic of Iran from 2005 to 2009. Others have no conflict of interest in the data presented in this manuscript.

\section{References}

1. Farkas S, Hackl C, Schlitt HJ. Overview of the indications and contraindications for liver transplantation. Cold Spring Harb Perspect Med. 2014;4(5) doi: 10.1101/cshperspect.a015602. [PubMed: 24789874].

2. Global Observatory On Donation And Transplantation(GODT). Organ Donation and Transplantation Activities 2014. Available from: http:// wwwtransplant-observatoryorg/data-reports-2014.

3. Singal AK, Fang X, Kaif M, Hasanin M, McGuire BM, Kuo YF, et al. Primary biliary cirrhosis has high wait-list mortality among patients listed for liver transplantation. Transpl Int. 2017;30(5):454-62. doi: 10.1111/tri.12877. [PubMed: 27754570]

4. Bachir NM, Larson AM. Adult liver transplantation in the United States. Am J Med Sci. 2012;343(6):462-9. doi: 10.1097/MAJ.ob013e3182308b66. [PubMed: 22683615].

5. Sapisochin G, Bruix J. Liver transplantation for hepatocellular carcinoma: outcomes and novel surgical approaches. Nat Rev Gastroentero Hepatol. 2017;14(4):203-17. doi: 10.1038/nrgastro.2016.193. [PubMed 28053342].

6. Ekser B, Mangus RS, Fridell W, Kubal CA, Nagai S, Kinsella SB, et al. A Novel Approach in Combined Liver and Kidney Transplantation With Long-term Outcomes. Ann Surg. 2017;265(5):1000-8. doi: 10.1097/SLA.0000000000001752. [PubMed: 28398965].

7. Sabet B, Rajaee-fard A, Nikeghbalian S, Malek-Hosseini SA. Six Years Liver Transplants Outcome in Shiraz Transplant Center. J Isfahan Med School. 2009;27(99).

8. Song AT, Avelino-Silva VI, Pecora RA, Pugliese V, D’Albuquerque LA, Abdala E. Liver transplantation: fifty years of experience. World J Gastroenterol. 2014;20(18):5363-74. doi: 10.3748/wjg.v20.i18.5363. [PubMed: 24833866].

9. Li J, Hansen BE, Peppelenbosch MP, De Man RA, Pan Q, Sprengers D. Factors associated with ethnical disparity in overall survival for patients with hepatocellular carcinoma. Oncotarget. 2017;8(9):15193204. doi:10.18632/oncotarget.14771. [PubMed: 28122352].

10. Pischke S, Lege MC, von Wulffen M, Galante A, Otto B, Wehmeyer MH, et al. Factors associated with long-term survival after liver transplantation: A retrospective cohort study. World J Hepatol. 2017;9(8):427-35. doi: 10.4254/wjh.v9.i8.427. [PubMed: 28357030].

11. Collett D, Friend PJ, Watson CJ. Factors Associated With Short- and Long-term Liver Graft Survival in the United Kingdom: Development of a UK Donor Liver Index. Transplantation. 2017;101(4):786-92. doi 10.1097/TP.0000000000001576. [PubMed: 27906826].
12. Pruinelli L, Monsen KA, Gross CR, Radosevich DM, Simon GJ, Westra BL. Predictors of Liver Transplant Patient Survival. Prog Transplant. 2017;27(1):98-106. doi: 10.1177/1526924816680099. [PubMed: 27888279].

13. IRODAT . International Registry in Organ Donation and Transplantation 2017. Available from: http://www.irodat.org/?p=database.

14. Lankarani $\mathrm{KB}$. The necessity of booster vaccination after neonatal hepatitis B vaccination. Hepat Mon. 2011;11(6):419-21. [PubMed: 22087171].

15. Lankarani KB, Mahmoodi M, Gholami S, Mehravar S, Malekhosseini SA, Heydari ST, et al. Reducing Social Disparity in Liver Transplantation Utilization through Governmental Financial Support. Hepat Mon. 2012;12(11):e6463. doi: 10.5812/hepatmon.6463. [PubMed: 23300495].

16. Flattau A, Olaywi M, Gaglio PI, Marcus P, Meissner P, L. Dorfman EB , et al. Social barriers to listing for adult liver transplantation: their prevalence and association with program characteristics. Liver Transpl. 2011;17(10):1167-75. doi: 10.1002/lt.22357. [PubMed: 21656658].

17. van der Hilst CS, Ijtsma AJ, Slooff MJ, Tenvergert EM. Cost of liver transplantation: a systematic review and meta-analysis comparing the United States with other OECD countries. Med Care Res Rev. 2009;66(1):3-22. doi: 10.1177/1077558708324299. [PubMed: 18981263].

18. Soyama A, Eguchi S, Egawa H. Liver transplantation in Japan. Liver Transpl. 2016;22(10):1401-7. doi: 10.1002/lt.24502. [PubMed: 27343152].

19. Iqbal M, Elrayah EA, Traynor O, McCormick PA. Liver transplantation in Ireland. Liver Transpl. 2016;22(7):1014-8. doi: 10.1002/lt.24456. [PubMed: 27065358].

20. Trotter JF. Liver transplantation around the world. Curr Opin Organ Transplant. 2017;22(2):123-7. doi: 10.1097/MOT.0000000000000392. [PubMed: 28151809].

21. Al Sebayel M, Abaalkhail F, Al Abbad S, AlBahili H, Elsiesy H, Aleid M, et al. Liver transplantation in the Kingdom of Saudi Arabia. Liver Transpl. 2017;23(10):1312-7. doi: 10.1002/lt.24803. [PubMed: 28650090].

22. Faraj W, Haydar A, Nounou GE, Naaj AA, Khoury G, Jabbour S, et al. Update on liver transplants in Lebanon. Prog Transplant. 2015;25(3):271-5. doi: 10.7182/pit2015810. [PubMed: 26308788].

23. Amer KE, Marwan I. Living donor liver transplantation in Egypt. Hepatobiliary Surg Nutr. 2016;5(2):98-106. doi: 10.3978/j.issn.23043881.2015.10.03. [PubMed: 27115003].

24. Adam R, McMaster P, O'Grady JG, Castaing D, Klempnauer JL, Jamieson $\mathrm{N}$, et al. Evolution of liver transplantation in Europe: report of the European Liver Transplant Registry. Liver Transpl. 2003;9(12):1231-43. doi: 10.1016/j.lts.2003.09.018. [PubMed: 14625822].

25. Moghaddasifar I, Lankarani KB, Moosazadeh M, Afshari M, Ghaemi A, Aliramezany M, et al. Prevalence of Non-alcoholic Fatty Liver Disease and Its Related Factors in Iran. Int J Organ Transplant Med. 2016;7(3):149-60. [PubMed: 27721961].

26. Alavian SM, Zamiri N, Gooya MM, Tehrani A, Heydari ST, Lankarani KB. Hepatitis B vaccination of adolescents: a report on the national program in Iran. J Public Health Policy. 2010;31(4):478-93. doi: 10.1057/jphp.2010.35. [PubMed: 21119653].

27. Alavian SM, Fallahian F, Lankarani KB. Implementing strategies for hepatitis B vaccination. Saudi J Kidney Dis Transpl. 2010;21(1):10-22. [PubMed: 20061687].

28. Yadav SK, Saraf N, Saigal S, Choudhary NS, Goja S, Rastogi A, et al High MELD score does not adversely affect outcome of living donor liver transplantation: Experience in 1000 recipients. Clin Transplant. 2017;31(8):e13006. doi:10.1111/ctr.13006.

29. Wronka KM, Grat M, Stypulkowski J, Bik E, Krasnodebski M, Masior L, et al. Liver Transplantation Outcomes in Recipients with High Model for End-Stage Liver Disease (MELD) Scores: The Relevance of MELD Scores. Ann Transplant. 2017;22:251-6. [PubMed: 28439063].

30. Soin AS, Goja S, Yadav SK, Tamang TY, Rastogi A, Bhangui P, et al. (D+10) MELD as a novel predictor of patient and graft survival after adult to adult living donor liver transplantation. Clin Transplant. 2017;31(5) doi: 10.1111/ctr.12939. [PubMed: 28239914]. 
31. Rostved AA, Lundgren JD, Hillingso J, Peters L, Mocroft A, Rasmussen A. MELD score measured day 10 after orthotopic liver transplantation predicts death and re-transplantation within the first year. Scand J Gastroenterol. 2016;51(11):1360-6. doi: 10.1080/00365521.2016.1196497. [PubMed: 27319374].

32. Bruix J, Gores GJ, Mazzaferro V. Hepatocellular carcinoma: clinical frontiers and perspectives. Gut. 2014;63(5):844-55. doi: 10.1136/gutjnl2013-306627. [PubMed: 24531850].

33. Jain A, Reyes J, Kashyap R, Dodson SF, Demetris AJ, Ruppert K, et al. Long-term survival after liver transplantation in 4,000 consecutive patients at a single center. Ann Surg. 2000;232(4):490-500. [PubMed: 10998647].

34. Wong LL, Limm W, Cheung A, Noguchi H. Liver transplant in Hawaii: the survival of a small centre. Clin Transplant. 2006;20(1):55-61. doi: 10.1111/j.1399-0012.2005.00440.x. [PubMed:16556154].

35. Kubota T, Hata K, Sozu T, Ueda Y, Hirao H, Okamura Y, et al. Impact of Donor Age on Recipient Survival in Adult-toadult Living-donor Liver Transplantation. Ann Surg. 2017 doi: 10.1097/SLA.0000000000002194. [PubMed: 28288061].

36. Chapman WC, Vachharajani N, Collins KM, Garonzik-Wang J, Park
Y, Wellen JR, et al. Donor Age-Based Analysis of Liver Transplantation Outcomes: Short- and Long-Term Outcomes Are Similar Regardless of Donor Age. J Am Coll Surg. 2015;221(1):59-69. doi 10.1016/j.jamcollsurg.2015.01.061. [PubMed: 25872684].

37. Rustgi VK, Marino G, Halpern MT, Johnson LB, Umana WO, Tolleris C. Role of gender and race mismatch and graft failure in patients undergoing liver transplantation. Liver Transpl. 2002;8(6):514-8. doi: 10.1053/jlts.2002.33457. [PubMed:12037781].

38. Marino IR, Doyle HR, Aldrighetti L, Doria C, McMichael J, Gayowski T, et al. Effect of donor age and sex on the outcome of liver transplantation. Hepatology. 1995;22(6):1754-62. [PubMed: 7489985].

39. Zhang Y. Impact of Donor Recipient Gender and Race Mismatch on Graft Outcomes in Patients With End-Stage Liver Disease Undergoing Liver Transplantation. Prog Transplant. 2017;27(1):39-47. doi: 10.1177/1526924816679839. [PubMed: 27895103].

40. Schoening WN, Helbig M, Buescher N, Andreou A, Bahra M, Schmitz $\mathrm{V}$, et al. Gender Matches in Liver Transplant Allocation: Matched and Mismatched Male-Female Donor-Recipient Combinations; Long term Follow-up of More Than 2000 Patients at a Single Center. Exp Clin Transplant. 2016;14(2):184-90. [PubMed: 27015533]. 